\title{
PRÁTICAS PEDAGÓGICAS NA EDUCAÇÃO INFANTIL: A MÚSICA COMO LINGUAGEM
}

Fernando Wolff Mendonça ${ }^{i} \oplus 0000-0002-6193-4793$

Universidade Estadual de Maringá - UEM

Diogo Almeida e Silva ${ }^{\text {ii }} \odot 0000-0003-2303-0272$

Universidade Estadual de Maringá - UEM

Resumo: É difícil definir a música e todo seu universo em poucas palavras ou em apenas uma concepção, considerando as suas inúmeras relações com o ser humano. Pensando em contribuir para a melhoria do trabalho educativo na educação infantil, propomos estudar práticas pedagógicas por meio da música. Visto que, as crianças estão sendo inseridas no ambiente escolar a partir dos 4 meses de vida, a responsabilidade do desenvolvimento infantil passa a ser compartilhada entre a família e instituição de escolar. Nesse sentido, a Lei de Diretrizes e Base da Educação Nacional LDBEN - de $\mathrm{n}^{\text {o }}$ 9.394/1996 e documentos nacionais, ressaltam a importância do trabalho pedagógico que promova o desenvolvimento integral da criança que está na creche ou na préescola. Diante desse contexto, esse trabalho tem por objetivo discutir as contribuições de práticas pedagógicas na educação infantil, abordando a música como linguagem, para o desenvolvimento das funções psicológicas superiores, ou seja, das aptidões humanas das crianças. Essa é uma pesquisa bibliográfica que faz uma revisão histórica sobre a música e sua relação com o homem e com a sociedade em que está inserida. Fundamentamo-nos no referencial da Teoria Histórico Cultural, propondo uma reflexão acerca de práticas pedagógicas que explorem o universo musical, para oportunizar diferentes formas do processo de humanização nas novas gerações.

Palavras-chave: Desenvolvimento Infantil. Linguagem. Música.

\section{PEDAGOGICAL PRACTICES IN CHILDHOOD EDUCATION: MUSIC AS LANGUAGE}

\begin{abstract}
It is difficult to define music and its entire universe in a few words or in just one conception, considering its innumerable relationships with human beings. Thinking of contributing to the improvement of educational work in early childhood education, we propose to study pedagogical practices through music. Since children are being inserted into the school environment from the age of 4 months on, the responsibility for child development is now shared between the family and the school institution. In this sense, the Law of Directives and Basis for National Education - LDBEN - of $\mathrm{n}^{\circ} 9.394$ / 1996 and national documents, emphasize the importance of pedagogical work that promotes the integral development of the
\end{abstract}

child who is in the nursery or preschool. Given this context, this work aims to discuss the contributions of pedagogical practices in early childhood education, addressing music as a language, for the development of higher psychological functions, that is, the human skills of children. This is a bibliographic research that makes a historical review about music and its relationship with man and with the society in which it is inserted. We are based on the framework of Cultural Historical Theory, proposing a reflection on pedagogical practices that explore the musical universe, to provide opportunities for different forms of the humanization process in new generations.

Keywords: Child development. Language. Music. 
DOI 10.33872/revcontrad.vlnl.e003 | v. 1, n. 1 | Jan./Jun. 2020

\section{Introdução}

A música é uma das manifestações artísticas mais conhecidas no contexto social em que vivemos. Ela alcança as pessoas de diversas formas, sejam no rádio do carro, propagandas nos meios de comunicação, nos notebooks, nos smartphones, shows, concertos musicais, a fim de atingir as e afetá-las de alguma forma, seja sua emoção, seu humor, seus pensamentos, isto é, tal manifestação implica na vida e na manifestação do homem.

A música surge das manifestações culturais desenvolvidas na história da humanidade. O homem primitivo, mesmo antes de manipular o fogo, de falar e de desenvolver outras aptidões humanas, se comunicava com gestos e sons ritmados, para satisfazer alguma necessidade individual à coletiva, então o que entendemos como música hoje, é "[...] resultado de longas e incontáveis vivências individuais e sociais” (SCHERER, 2010, p. 1).

Observamos que a música assume uma função primordial no desenvolvimento do psiquismo humano. Os estudos de Rocha e Boggio (2013), acerca da neurociência, abordam várias pesquisas envolvendo a música, em diversas áreas, das quais se destacam a percepção auditiva, a relação entre música e movimento, a relação entre música e memória, estudos com música e linguagem, além das emoções evocadas por música.

Além disso, essas investigações têm apontado para o papel da música como ferramenta de intervenção em diferentes alterações neurológicas como afasia, autismo e dislexia. Porém, nesse trabalho abordamos a música enquanto linguagem, com o objetivo de compreendê-la como produto das relações humanas, construída historicamente, que contribui para a humanização homem, ou seja, para o desenvolvimento do psiquismo humano.

Desse modo, primeiramente, será necessário compreender o processo histórico da música, seu surgimento com o homem primitivo, suas transformações, sua relação com cada civilização em que está inserida e sua relação com o ser humano. Autores como Ellmerich (1973), Jeandot (1997), Freire (1994) e Bennett (1986) auxiliam nossos estudos nessa retomada histórica. Em seguida, será abordada uma revisão conceitual fundamentada no referencial teórico da Teoria Histórico Cultural, utilizamos ideias de autores como Leontiev (2004), Vigotski (1998), Mendonça (2017) dentre outros.

No terceiro tópico, falaremos sobre a música como linguagem, uma perspectiva diferente, que permite inúmeras formas de trabalho na área da educação e do desenvolvimento humano, por meio da música. No quarto tópico, apresentaremos um breve histórico sobre a educação infantil e uma relação de práticas pedagógicas com o universo musical e conceitos 
DOI 10.33872/revcontrad.vlnl.e003 | v. 1, n. 1 | Jan./Jun. 2020

sobre o processo de humanização do homem. Por fim, concluímos os estudos aqui apresentados, acerca do tema que foi tratado nesse trabalho.

\section{A música e o homem: apontamentos históricos}

A música nem sempre foi da forma como conhecemos nos dias de hoje. Partimos da premissa que a música se constitui basicamente de uma sucessão de sons e silêncio organizada ao longo do tempo. Autores como Jeandot (1997), Freire (1994) e Ellmerich (1973), consideram-na como uma manifestação cultural e humana. Atualmente, desconhecem-se civilizações ou agrupamentos que não possua manifestações musicais próprias. Contudo, não há apenas essa finalidade para a música, visto que ela também pode ser considerada como uma forma de arte, considerada por muitos como sua principal função.

Com base em Ellmerich (1973), compreendemos que a música, como ideia organizada e possível de ser transmitida aos outros, surgiu há cerca de 50.000 anos com o homem pré-histórico. Iniciou com sons dos tambores, ritmo das danças, batidas de pés no chão, palmas, sons dos colares e braceletes. Essas manifestações serviam para festejar ou estimular uma boa colheita, uma boa caçada, a fertilidade da terra e dos homens, estabelecer contato com a natureza por meio da imitação de seus sons, comunicar-se com deuses ou seus ancestrais.

Associada à dança, a música também assumia um caráter ritualístico, inclusive com funções mágicas. Os elementos básicos da música já estavam presentes, som e ritmo, assim como também no ser humano o pulsar do coração, a respiração e o passo. A predominância do ritmo, agindo com grande poder sobre o corpo, proporcionava movimento coletivo no seu aspecto socializante. Mesmo sendo, inicialmente, um tanto primitivas, essas atividades eram intensas em significado, com envolvimento da família e da tribo. Os instrumentos primitivos eram pouco melodiosos, produzindo sonoridades roucas, barulhentas, ou apenas emitindo ruídos.

Com o passar do tempo o homem foi aprimorando a forma de fazer música, isso tinha relação com a cultura local, que influencia nos tipos de música e na finalidade da mesma. Como por exemplo, para os povos gregos, egípcios e árabes a palavra música significa "a arte das musas", na mitologia grega. As musas eram seres celestiais ou divindades que inspiraram as artes e as ciências e tinham Orfeu, filho de Apolo, como seu deus. Orfeu foi, na mitologia grega, o Deus da música. Já na Roma antiga, a música não atingiu grande desenvolvimento, como podemos ver na obra História da música, de Ellmerich (1973), em que diz: 
DOI 10.33872/revcontrad.vlnl.e003 | v. 1, n. 1 | Jan./Jun. 2020

[...] os romanos não alcançaram grande desenvolvimento nas artes em virtude de sua tendência guerreira e de constantes preocupações nas lutas de conquista. Assim o florescimento artístico romano começa com subjugação da Grécia em 146 a.c. (ELLMERICH, 1973, p. 26-27).

Já na Idade Média, encontramos um mundo dominado pelo fanatismo religioso, Ellmerich (1973) escreve que, esse cenário de fanatismo extremo levou àquele período histórico quase total estagnação. O canto gregoriano que é um estilo de música cristão, composto por um sistema silábico que nomina as notas musicais. A igreja católica sentia necessidade naquele momento histórico de sistematizar esse rito religioso, para não haver desagregação mesmo nas regiões mais distantes. Essa música era simbólica, ou seja, usava de símbolos quando cantada nos cerimoniais da igreja Romana. Os fiéis cantavam uma mesma melodia em uníssono, aguda e bem alta, que simbolizava o encontro com o altíssimo, isto significava a unidade da igreja.

Esses são exemplos de como a músicas tem a relação com o momento sócio-histórico a qual ela pertence. Historicamente, a música com direcionamento escolar não estava envolvida na educação das crianças, essa função da música é dos tempos mais recentes. A historiografia da música é muito complexa, pois se diferencia entre as civilizações, alguns ramos dessa história estudam as origens e a evolução de tal manifestação ao longo do tempo, outras investigações, caminham para a teoria musical e a musicologia.

Todas estas concepções trabalham a arte como "sintoma", como manifestação de "outra coisa" (Espírito, Cultura, Sociedade) e não como elemento integrante da construção da própria História. Desconhecem, também, a heterogeneidade e descontinuidade das sociedades, das ideologias que, nelas, se imbricam (FREIRE, 1994, p. 154).

Desta forma, esboçamos a centralidade da discussão desse trabalho, analisar a música enquanto “[...] elemento integrante da construção da própria História” (FREIRE, 1994, p. 154), enquanto agente influenciador da humanização do ser humano. Embora não consigamos estabelecer seu desenvolvimento de forma precisa, a instituição e a evolução da música confundem-se, com a própria história do desenvolvimento do homem. Evidente que essa relação é fundamental para compreendermos os processos de desenvolvimento humano. A base dessa investigação está na era primitiva, do desenvolvimento do psiquismo humano. Para tanto é necessário levantarmos fundamentos sobre a perspectiva de desenvolvimento humano, no qual iremos nos estruturar. 
DOI 10.33872/revcontrad.vlnl.e003 | v. 1, n. 1 | Jan./Jun. 2020

\section{O homem e a cultura: contribuições da teoria histórico cultural}

Diante do pequeno histórico esboçado anteriormente, notamos que o conceito de música se expandiu com o passar do tempo e atualmente se encontra em diversas utilidades não só como arte, mas também como a militar, educacional ou terapêutica (musicoterapia). Além disso, não perdeu suas características primitivas de estar presentes em atividades coletivas, como os rituais religiosos, festas, funerais e etc. Essas relações coletivas são o marco para o desenvolvimento do homem em ser humanizado.

Precursores da Teoria Histórico Cultural (THC), defende que o homem não nasce humanizado, mas ele aprende a ser humano por meio de suas relações com outros seres humanos e da apropriação da herança cultural produzida e acumulada pela a espécie em sua história. "[...] o homem é um ser de natureza social, que tudo o que tem de humano nele provém de sua vida em sociedade, no seio da cultura criada pela humanidade (LEONTIEV, 2004, p. 279)". Constata-se que o desenvolvimento humano é um processo dialético em que o homem, por meio da sua ação e de instrumentos, modifica a natureza para suprir suas necessidades e ao mesmo tempo modifica a si mesmo.

As aquisições do desenvolvimento histórico das aptidões humanas não são simplesmente dadas aos homens nos fenômenos objetivos da cultura material e espiritual que os encarnam, mas são aí apenas postas. Para se apropriar destes resultados, para fazer deles as suas aptidões [...] A criança, o ser humano, deve entrar em relação com os fenômenos do mundo circundante através de outros homens, isto é, num processo de comunicação entre eles. Assim, a criança aprender a atividade adequada. Para sua função este processo é, portanto, um processo de educação (LEONTIEV, 2004, p. 290).

Nesse sentido, o trabalho educativo é fundamental para o desenvolvimento das especificidades do ser humano das novas gerações. A relação dos bebês com adultos ou com os educadores, na educação infantil, devem propiciar esse processo. É o ensino das especificidades humanas que irá desenvolver as aptidões humanas nos bebês.

Essa prática de humanização, que acontece por meio de um processo de educação, é fundamentada por conceitos elaborados na teoria de Vigotski (1896 - 1934), no qual o desenvolvimento humano ocorre do externo para o interno. 
DOI 10.33872/revcontrad.vlnl.e003 | v. 1, n. 1| Jan./Jun. 2020

Os saberes produzidos pelo grupo social serão transmitidos em um processo mediado pelos signos (linguagem) para que o grupo em formação possa desenvolver-se do ponto de vista cognitivo em um processo por meio do qual se [...]. O processo, que Vigotski chama de internalização, se dá quando "as relações intrapsíquicas (atividade individual) se constituem a partir das relações Inter psíquicas (atividade coletiva)" (MOURA et al., 2010, p. 208 apud MENDONÇA, 2017, p. 94). É por meio do movimento do social para o individual, mediado pela linguagem, que se promove a aprendizagem das experiências sociais humanas (MENDONÇA, 2017, p. 94).

Tais conceitos, são necessários para o entendimento do processo de humanização do ser humano, que acontece nas relações coletivas. Esse processo ocorre do ambiente externo e se consolida na internalização psíquica, que resulta na aprendizagem das aptidões humanas. Essas relações são responsáveis pelo o desenvolvimento das funções psicológicas superiores, que são exclusivas dos seres humanos.

De acordo com Vigotski (1998), as Funções Psicológicas são as capacidades ou propriedades de ação de que dispõe o psiquismo no processo de captação da realidade objetiva. As funções elementares são comuns ao homem e a outros animais, já que são próprias do organismo biológico, assim várias espécies de animais tem a capacidade de sentir, perceber, atentar etc.

Já as Funções Psicológicas Superiores são exclusivas dos seres humanos, a atenção voluntária, a imaginação, o planejamento, a memória voluntária, percepção, pensamento, linguagem simbólica, sentimentos, etc. pois elas resultam das relações sociais e caracterizam o comportamento consciente do homem, assim explica Vigotski (1998):

O conceito de "desenvolvimento das funções psíquicas superiores" é objeto de nosso estudo abarcam dois grupos de fenômenos [...] Trata-se, em primeiro lugar, de processos de domínio dos meios externos do desenvolvimento cultural e do pensamento: a linguagem, a escrita, o cálculo, o desenho; e, em segundo, dos processos de desenvolvimento das funções psíquicas superiores especiais, não limitadas nem determinadas com exatidão, que na psicologia tradicional denominam-se atenção voluntária, memória lógica, formação de conceitos, etc. Tanto uns como outros, tomados em conjunto, formam o que qualificamos convencionalmente como processos de desenvolvimento das formas superiores de conduta da criança (VIGOTSKI, 1998, p. 29).

Desse modo, o que diferencia o homem dos animais é o fato do primeiro ter o controle consciente de sua conduta, ter a habilidade de planejar uma ação e executá-las conscientemente e poder refletir sobre elas. É importante assegurar que o desenvolvimento de tais funções é decorrente do processo de mediação nas relações sociais. 
DOI 10.33872/revcontrad.vlnl.e003 | v. 1, n. 1 | Jan./Jun. 2020

A mediação diz respeito ao momento em que um indivíduo mais "experiente", na relação com outro "menos experiente", compartilham vivências, mobilizando as funções psicológicas superiores, no qual no final da interação ambos saiam mais "experientes", da forma que apontam Mendonça e Paula (2009, p. 68):

Quando se diz que o adulto faz a mediação do conhecimento para a criança, isso significa afirmar que a relação da criança com uma informação recebida não é uma relação direta, mas uma relação mediada pelo adulto. [...]. Dessa maneira, a criança vai construindo significados a partir das interações mediadas pelos adultos.

De acordo Vigotski (1998), o desenvolvimento se produz por meio de aprendizagens, portanto não há o que se desenvolver sem que se ensine, mas há de se ensinar para desenvolver algo. O processo de mediação ocorre no intervalo de Zona de Desenvolvimentos Real - ZPR - e Zona de Desenvolvimento Potencial - ZDP, no qual Vigotski (1998) assegura que, a primeira corresponde aquilo que o sujeito já sabe fazer sozinho, a segunda aquilo que o sujeito pode vir a fazer, com a mediação necessária, para tanto, de modo a fazer disso um ciclo de aprendizagem.

[...] referindo-se ao dinamismo do desenvolvimento psíquico, postula-o como expressão de entrelaçamento do nível de desenvolvimento efetivo; representando aquilo que a criança é capaz de fazer por si mesma graças a habilidades já desenvolvidas; e a área de desenvolvimento potencial; compreendendo o que pode fazer com o auxílio dos adultos por conta de processos de desenvolvimento em curso, sobre o qual o ensino deve incidir (VIGOTSKY, 2001, p. 112 apud MARTINS, 2009, p. 76).

Nesse sentido, o conceito da ZDP e os demais conceitos referentes ao desenvolvimento do psiquismo e forma de aprendizagem são de suma importância para essa investigação, já que estamos falando do desenvolvimento infantil.

\section{A música como linguagem}

É difícil definir o que seja música com poucas palavras sem considerar as inúmeras relações dela com o ser humano. Nem sempre os estudos e as pesquisas sobre tal manifestação humana chegam às conclusões unânimes. Segundo Jenadot (1997): 
DOI 10.33872/revcontrad.vlnl.e003 | v. 1, n. 1 | Jan./Jun. 2020

Para Wagner, a música é "a linguagem do coração humano". Esse conceito nos leva à ideia de ritmo, que é o elemento básico das manifestações da vida e também um princípio fundamental da música. Alguns povos podem desconhecer a melodia e a harmonia, mas nenhum desconhece o ritmo. O conceito de música varia de cultura para cultura (JEANDOT, 1997, p. 12).

Nesse sentido, a música é uma linguagem universal, que não segue um padrão ou um estereótipo, pois varia entre as culturas. Não obstante, a música pode ser abordada como linguagem, já que ela supre a necessidade de comunicação, dos homens primitivos, antes mesmo da surgimento da fala, “[...] mesmo antes da descoberta do fogo, o homem primitivo se comunicava por meio de gestos e sons rítmicos, sendo, portanto, o desenvolvimento da música, resultado de longas e incontáveis vivências individuais e sociais" (SCHERER, 2010, p. 1).

Ao tratarmos a música como linguagem, é importante expor o conceito de linguagem aludido nesse trabalho. Assim, entende-se por linguagem, toda forma de comunicação que o homem veio a desenvolver na sua história. Segundo os precursores da THC, a linguagem tem a função de meio de comunicação e também de veículo de conhecimento, isso por conta da forma de seu surgimento nas relações de trabalho coletivo, e do seu papel no processo de humanização.

As formas de linguagem, o desenho, os gestos, palavras cantadas, a palavra oral ou palavra escrita trazem consigo ideias. Ao apropriar-se dessas ideias, a criança se insere na história da humanidade e se transforma à medida que se relaciona com a sociedade. Nesse sentido, o desenvolvimento da linguagem é o precursor do desenvolvimento do pensamento, pois, o mesmo é produto das ideias e das significações elaboradas decorrente das transformações psíquicas ocasionadas pela linguagem. Nesse ponto de vista, concordamos que:

[...] o processo de apropriação dessa linguagem ultrapassada a dimensão natural, isto é, o que foi dado pela natureza no nascimento da criança não é o suficiente para o desenvolvimento da linguagem, as condições biológicas não desenvolvem essa habilidade social (MENDONÇA, 2017, p. 51).

Nesse sentido, criança desenvolve a linguagem no meio social e na relação com outros seres humanos, configurando, segundo Vigotski (1998), uma aprendizagem do que ne inicia na função interpsíquica, - relação com o externo, com outros humanos, com o coletivo -, e se consolida na função intrapsíquica - quando a criança e internaliza o que aprendeu. 
DOI 10.33872/revcontrad.vlnl.e003 | v. 1, n. 1 | Jan./Jun. 2020

$\mathrm{Na}$ educação escolar, esse processo de apropriação da linguagem, bem como de apropriação de todos os outros conhecimentos produzidos historicamente pelo homem é um processo mediado pelo professor. É fundamental que o docente compreenda isso para saber qual a sua função dentro da sala de aula.

Desta forma, a música enquanto linguagem e expressão artística, foi e é fundamental para o desenvolvimento do psiquismo humano, pois o ser humano desde a pré-história, se relaciona com as expressões artísticas.

O homem sempre teve a necessidade de representar, através da expressão corporal, visual, plástica, musical, a sua realidade. Uma condição manifestada com o coletivo, que utiliza formas para registrar a apreensão do real e como apreende e se reconhece o mundo. Com isso, realiza a transposição do seu pensamento para uma linguagem artística. Assim, tal linguagem tornou-se símbolos construídos socialmente a fim de responder às necessidades do coletivo (BARROS, 2019, p. 130).

Desse modo, toda forma de expressão artística se relaciona com a consciência humana que é, portanto, um produto dos estímulos, das relações sociais que oportunizam a humanização do homem. "A arte é o trabalho do pensamento, mas de um pensamento emocional inteiramente específico" (VIGOTSKI, 2001, p. 57), isto é, a arte carrega consigo valores sociais, culturais que se transformam em símbolos de comunicação do comportamento humano.

Concebendo a música com linguagem, ela apresenta uma ação intencional do homem, mesmo que de forma abstrata e justificada pelo trabalho intelectual que o homem realiza, faz dela um trabalho humano. Assim, podemos assegurar sua importância no desenvolvimento das funções psicológicas superiores, ou seja, no desenvolvimento das aptidões humanas.

[...] No processo de criação e construção, [...] o homem revela o seu grande potencial de representar, ora o universo coletivo das relações sociais, ora o universo compreendido pelo psiquismo individual. [...] É por meio do processo mediatizado, entre homem e a arte, que ele internaliza e expressa a sua sensibilidade e promove o desenvolvimento cognitivo das funções psicológicas superiores (BARROS, 2019, p. 134).

Nessa passagem, Barros (2019) se refere à arte, porém no contexto deste trabalho podemos nos especificar na música. Nesse sentido, a criança que entra em contato com a música, abordada como linguagem e mediatizada de forma consciente por um adulto, ou pelo educador, mobiliza a criança no processo de desenvolvimento humano e cognitivo. 
DOI 10.33872/revcontrad.vlnl.e003 | v. 1, n. 1 | Jan./Jun. 2020

Nos dias atuais, a criança tem muito contato com música. Já no nascimento, a criança é imersa em um universo sonoro. Os sonos dos aparelhos médicos, ou dos aparelhos domésticos, já são sentidos pela criança. $\mathrm{O}$ canto ritmado junto ao balanceio da mãe, afeta sensível e sensorialmente o bebê que acalma e adormece. "Na verdade, [...] ainda no útero materno, a criança já toma contato com um dos elementos fundamentais da música - o ritmo -, através das pulsações do coração de sua mãe" (JEANDOT, 1997, p. 18).

Antes de começar a falar palavras, é possível ver a criança experimentado os sons que ela consegue emitir pela boca, ela cantarola, gorjeia, emiti sonos ritmados, na tentativa de se comunicar oralmente.

[...] Observando uma criança pequena, podemos vê-la cantarolando um versinho, uma melodia, ou emitindo algum som repetitivo e monótono, balançando-se de uma perna para a outra, ou ainda para frente e parra trás, como que reproduzindo o movimento de acalanto. Essa movimentação bilateral desempenha papel importante em todos os meios de expressão que utilizam do ritmo, seja a música, a linguagem verbal, a dança, etc. (JEANDOT, 1997, p. 18).

Nesse sentido, a música é instrumento fundamental para o desenvolvimento da linguagem oral, além de outras contribuições acerca do desenvolvimento cognitivo, sensorial e motor da criança. As crianças pequenas, assim como as mais velhas, adolescentes, jovens, adultos, idosos enfim, pessoas de toda as idades, tendem a acompanhar as músicas com movimentos com o corpo, sejam com a dança organizada, ou com batidas tímidas com os pés, palmas, volteios de cabeça e etc.

Desta forma, asseguramos que:

“[...] é a partir dessa relação entre o gesto e o som que a criança - ouvindo, cantando, imitando, dançando - constrói seu conhecimento, percorrendo o mesmo caminho do homem primitivo na exploração e na descoberta dos sons" (JEANDOT, 1997, p. 19).

Desse modo, além dos movimentos corporais, as músicas afetam os humanos de forma sentimental e intelectual, de modo que sua utilização como meio de produção de conhecimento faz de si uma ferramenta indispensável, que abre inúmeras possibilidades de práticas pedagógicas para o trabalho educativo no processo de humanização.

\section{A educação infantil e o processo de humanização: práticas pedagógicas explorando a música}


DOI 10.33872/revcontrad.vlnl.e003 | v. l, n. 1 | Jan./Jun. 2020

A trajetória histórica da educação infantil é marcada por muitas mudanças até ser entendida e vivenciada da forma que é hoje. Momento em que deixa de ser entendida como uma etapa assistencialista, preocupada apenas no cuidar das crianças. As creches e pré-escolas que antes eram vistas como um "depósito" de crianças, lugar onde elas ficavam para os pais poderem trabalhar, hoje são vistas com um cunho educacional, que vai além do cuidar. Atualmente essas instituições são consideradas de suma importância para o desenvolvimento integral da criança. O cuidar agora tem uma relação intrínseca com o educar.

Desse modo, analisando o percurso histórico da Educação Infantil, notamos que a preocupação com a essa etapa da educação básica iniciou tardiamente, decorrente do crescimento urbano e a transformação do mercado de trabalho, em que as mulheres (mães) precisavam trabalhar para complementar a renda familiar e não tinham local para deixar seus filhos. Diante desse fato, surgiram então as primeiras ideias de infância e educação infantil, porém, uma educação voltada apenas para o cuidado, é neste contexto que surgiram as primeiras creches e pré-escolas.

Eram as creches que surgiam, com caráter assistencialista, visando a afastar as crianças pobres do trabalho servil que o sistema capitalista em expansão lhes impunha, além de servirem como guardiãs de crianças órfãs e filhas de trabalhadores. Nesse sentido, a pré-escola tinha como função precípua a guarda das crianças (ABRAMOVAY; KRAMER, 1981, p. 29).

De início as creches e pré-escolas traziam um caráter assistencialista, visando apenas o cuidado da criança na ausência da família. Neste período, a criança era vista como um ser frágil, indefeso e totalmente dependente. Como apenas bastava cuidar, os profissionais não possuíam nenhum tipo de formação e sua função era apenas os cuidados de higiene e regras de comportamento.

Porém, crescimento do mercado de trabalho e dos modos de produção evoluíram, sendo necessário o aumento de escolas e pré-escolas para suportar a demanda de crianças. Nesse contexto, a educação pré-escolar não poderia apenas cuidar, mas deveria suprir uma carência cultural, eis então um novo modelo de educação: “educação compensatória”, em que promoviam o atendimento para crianças de classes mais baixas, preparando-as para a alfabetização.

Com o aumento da demanda de pré-escolas, a educação infantil passou por um processo de municipalização. Já não podia apenas ter caráter assistencialista ou compensatório, mas deveria ter funções educativas. Com a Constituição de 1988 (BRASIL, 1988), a educação foi reconhecida como direito de todos e dever do Estado. Com o Estatuto 
DOI 10.33872/revcontrad.vlnl.e003 | v. 1, n. 1 | Jan./Jun. 2020

da Criança e do Adolescente - ECA - (BRASIL, 1990), os direitos de crianças e adolescentes foram concretizados perante a lei. A Lei de Diretrizes e Bases da Educação Nacional LDBEN - n 9.394/96, em seu artigo Art. 29, pontua que:

A educação infantil, primeira etapa da educação básica, tem como finalidade o desenvolvimento integral da criança de até 5 (cinco) anos, em seus aspectos físico, psicológico, intelectual e social, complementando a ação da família e da comunidade (BRASIL, 1996).

Com a legislação, a Educação Infantil passa a ter um novo significado na sociedade, como também a valorização da criança como sujeito social e a importância da formação de profissionais para atuar nesta área.

A LDBEN (1996) e as Diretrizes Curriculares Nacionais para a Educação Infantil DCNEI - (BRASIL, 2010), traz que a educação infantil deve proporcionar um desenvolvimento nos aspectos físico, intelectual, psicológico e social, desta forma, a proposta pedagógica para essa etapa de ensino, deve ser consistente para esse desenvolvimento. Portanto, as creches e pré-escolas e instituições públicas ou privadas que ofertam a educação infantil, devem ter um suporte teórico, embasado em leis e documentos, para que esse ensino não seja assistencialista, mas que seja uma etapa educacional. O DCNEI - (BRASIL, 2010), apresenta uma proposta pertinente, pois relaciona os conteúdos escolares com à realidade dos alunos, trazendo características importantes para o desenvolvimento psíquico-social das crianças, como a brincadeira e a ludicidade.

Relacionando o histórico e a concepção de educação infantil, com o processo de humanização com o contexto da atual sociedade, podemos observar que, de fato, o desenvolvimento das Funções Psicológicas Superiores é potencializado pelas atividades desenvolvidas com a criança, que na maioria das vezes está no ambiente escolar.

Na prática, é notável que as crianças estejam iniciando a vida escolar cada vez mais cedo. Por diversos motivos influenciados pela a estrutura da sociedade capitalista, observamos a necessidade da ausência dos responsáveis pela criança (pais ou familiares), que consequentemente, essa vai para o CEI - Centro de Educação Infantil - na mais terna idade.

Essas instituições estão regulamentadas perante a legislação nacional e por documentos oficiais, para o atendimento de crianças a partir de 4 meses de idade. Nesses casos, crianças com menos de 1 ano de vida, já estão passando em torno de 8 horas por dia no CEI. Porém, isso não tira dela o direito do desenvolvimento infantil adequado. Dentro da instituição escolar, é função do educador contribuir e assegurar, à criança, atividades, que 
DOI 10.33872/revcontrad.vlnl.e003 | v. 1, n. 1 | Jan./Jun. 2020

devem ser mediadas por meio do trabalho educativo, que possibilitem o seu desenvolvimento psíquico, sua humanização, enfim, seu desenvolvimento infantil.

Desse modo, todos os conceitos levantados e descritos anteriormente, tanto referentes ao processo de humanização, quanto as concepções que embasam o trabalho com a educação infantil, estão intrinsicamente relacionados com a atividade humana e o trabalho educativo. Diante disso, podemos analisar formas diferentes de práticas educativas, que enriqueçam o trabalho pedagógico dos docentes, como por exemplo o uso de objetos.

Ao entrar em contato com os objetos, ela, rapidamente começa a interagir com o mundo sonoro, que é o embrião da música, e, nessa medida, qualquer objeto que produz ruído torna-se para ela um instrumento musical capaz de prender sua atenção por muito tempo (JEANDOT, 1997, p. 19).

Nesse trecho, a autora fala sobre os objetos, o quais são "peça chave" no desenvolvimento humano. Relacionando com os estudos da THC sobre a aquisição das habilidades especificamente humanas, entendemos que a criança é inserida em um mundo com objetos criados pelo homem, o contato e o domínio desses objetos que dão a possibilidade dela se desenvolver.

Para se apropriar dos objetos ou dos fenômenos que são o produto do desenvolvimento histórico, é necessário desenvolver em relação a eles uma atividade que reproduza, pela sua forma, os traços essenciais da atividade encarnada, acumulada no objeto. [...] o instrumento é ao mesmo tempo um objeto social no qual estão incorporadas e fixadas as operações de trabalho historicamente elaboradas (LEONTIEV, 1978, p. 266).

Confrontando os estudos de Jeandot (1997) e Leontiev (1978), notamos que ambos falam sobre a importância dos objetos, porém com conceitos e contextos diferentes, nesse caso, observamos que no âmbito dessa pesquisa, os dois conceitos se relacionam e se complementam. Isso pelo fato dos objetos, serem uma criação histórica da humanidade e instrumento de humanização das novas gerações e o contato das crianças com esses, introduz a criança no mundo sonoro. Imersa nesse mundo, a criança tem a possibilidade de desenvolver-se humanamente, com a presença de um adulto, ou do educador, mediando o processo adequadamente.

A mediação nesse processo e tão importante quando os objetos. A criança recém inserida no mundo objetal, não sabe a função social de cada objeto, para a apropriação correta de determinada função é necessário um processo educativo. Este pode ser efetivado pela própria família que ensina a criança a utilizar o objeto de forma que ele cumpra sua função. 
DOI 10.33872/revcontrad.vlnl.e003 | v. 1, n. 1 | Jan./Jun. 2020

Mas, esse trabalho educativo deve acontecer também nas instituições de educação infantil, os educadores e demais profissionais que atuam nesse nível da educação, devem conhecer as especificidades de tal processo para desenvolvê-lo adequadamente.

Nesse sentido, “[...] o ensino bem estruturado promove desenvolvimento mental" (MENDONÇA, 2017, p. 46), ou seja, o trabalho educativo fundamentado teoricamente, pensado e planejado, promove o desenvolvimento intelectual do aluno. Assim, os profissionais da educação infantil, devem pensar em práticas pedagógicas que permitam dar possibilidade de desenvolvimento às crianças

Constata-se a necessidade do educador saber propor atividades que permitam o desenvolvimento do processo educacional. Pensando nas práticas pedagógicas com a música, “[...] Ao adulto caberá compreender em que medida a música constitui uma possibilidade expressiva privilegiada para a criança, uma vez que atingi diretamente sua sensibilidade afetiva e sensorial" (JEANDOT, 1997, p. 20).

O docente, deve conceber a criança como um ser ativo no desenvolvimento, para propor atividades que permitam que ela tenha experiência com objetos e com a música. Deixar o discente fazer de objetos, instrumentos musicais, deixar que o mesmo tente cantarolar ritmos, e quando lhe parecer difícil, usar de seu conhecimento para mediar a apropriação da nova habilidade.

Jeandot (1997), descreve uma situação presenciada que podemos tomar como exemplo de prática pedagógica:

Certa vez, numa classe de crianças de 2 a 4 anos, ao se colocarem à disposição delas, pedaços de papel de vários tipos, uma menina de 2 anos, depois de manipulá-los, foi se sentar num canto da sala levando uma cartolina, que ela revirava entre os dedos. A cadência regular produzia uma sucessão de sons repetidos, alternados por curtos momentos de silêncio. Eu a observei por algum tempo, e em seguida aproximei dela um tambor e duas baquetas. Qual não foi minha surpresa ao ouvir a mesma cadência dos sons no tambor, produzida ainda com alternância de braços, o que é raro nessa idade! De fato, ela estava prestando atenção no som que realizava (JEANDOT, 1997, p. 20).

Diante do relato, observamos a importância da musicalidade na estimulação das funções psicológicas superiores. Nesse exemplo, notamos o trabalho com atenção voluntária e da coordenação motora. Tal prática constatou que a criança estava concentrada no ritmo que executava, e após tomar o tambor e baquetas em suas mãos, o estimulo se intensificou e passou na abstração mental, perante o ritmo, para a prática motora, com um nível de complexidade acentuado, por conta da alternância de braços. 
DOI 10.33872/revcontrad.vlnl.e003 | v. 1, n. 1 | Jan./Jun. 2020

Esse trabalho pode se intensificar de modo a oportunizar ainda mais o desenvolvimento das especificidades humanas da criança, só depende do planejamento e da articulação do educador que media a atividade. Por exemplo, após o domínio do ritmo por meio do tambor e baquetas, propor que o aluno, execute o ritmo com o corpo, batendo palmas. Em seguida, pode-se dar o comando para o discente reproduzir o ritmo com a voz, utilizando uma letra ou uma sílaba. Desta forma, a música está sendo utilizada para o desenvolvimento das funções psicológicas superiores, bem como para a formação de conceitos. Trabalha-se a linguagem; articulação som/silencio na fala; partes do corpo; atenção e concentração; ritmo; etc.

\footnotetext{
Música é linguagem. Assim, devemos seguir em relação à música, o mesmo processo de desenvolvimento que adotamos quanto a linguagem falada, ou seja, devemos expor a criança à linguagem musical e dialogar com ela sobre e por meio da música. [...] o educador, antes de transmitir sua própria cultura musical, deve pesquisar o universo musical a qual a criança pertence, e encorajar atividades relacionadas com a descoberta e com a criação de novas formas de expressão através da música (JEANDOT, 1997, p. 20).
}

Abordar a música enquanto linguagem, é fundamental e enriquece as possibilidades de desenvolvimento das funções psicológicas superiores, de modo a potencializar a humanização e o desenvolvimentos cognitivo da criança. O professor, nesse sentido, deve ser criativo, de modo que consiga mobilizar a motivação da criança, construindo novas possibilidades de aprendizado e mediando as atividades dos alunos quando necessário.

O trabalho educativo na educação infantil, deve acontecer principalmente por meio de jogos e brincadeiras, conscientemente preparadas e planejadas, a fim de explorar a imaginação e a socialização, bem como outros aspectos das crianças, para enriquecer o seu desenvolvimento. Desta forma, tais práticas podem motivar o interesse dos discentes na atividade e despertar um prazer na execução da mesma.

Diante disso, jogos e brincadeiras diretamente relacionados com a música, são instrumentos fundamentais a serem trabalhados na educação infantil. Pois se trata de atividades divertidas, as quais mobilizam a atenção e imaginação dos alunos, bem como intensificando o desenvolvimento da linguagem, da coletividade, dos processos cognitivos, construção de conceitos e de outras especificidades humanas. Assim, segundo Jeandot (1997), é fundamental o trabalho com jogos e brincadeiras musicais na escola, para observar a grande influência que a música exerce sobre a criança. 
DOI 10.33872/revcontrad.vlnl.e003 | v. 1, n. 1 | Jan./Jun. 2020

Nesse contexto, ressaltamos a necessidade de se trabalhar com músicas ou brincadeiras, adequadas para cada faixa etária dos educandos, a fim de que essas práticas promovam o desenvolvimento infantil. $\mathrm{O}$ mundo midiático e a indústria musical tendem a executar e reproduzir estilos musicais que estimulem o mercado financeiro, e na maioria das vezes, é com esses estilos musicais que a criança tem contato tanto em casa como na escola.

Nesse sentido, cabe ao professor, ter consciência e conhecimento para colocar seu trabalho em prática, de modo a não desconsiderar totalmente o universo musical que a criança esteja inserida, mas saber priorizar a necessidade dela, e abordar o que realmente ela precisa. Se a música com a qual a criança está em contato no ambiente social, é adequada para o trabalho que o professor irá desenvolver, em uma determinada faixa etária, seja ela com ritmos mais intensos, incorporadas por maior número de palavras, o mesmo pode utilizá-la.

Entretanto, se tratando do trabalho com os bebês, é evidente que a necessidade sejam músicas com ritmos menos intensos, com poucas palavras, para a estimulação de funções que ainda estão em construção. Nesse sentido, o docente tem a função de:

[...] antes de transmitir sua própria cultura musical, deve pesquisar o universo musical a que a criança pertence, e encorajar atividades relacionadas com a descoberta e com a criação de novas formas de expressão através da música. [...] Ao educador caberá enriquecer seu repertório musical com discos e materiais para serem explorados, observar o trabalho de cada criança e planejar atividades que envolvam músicas de diferentes povos, de diferentes épocas, de diferentes formas, de diferentes compositores, etc. (JEANDOT, 1997, p. 20-21).

Assim, o trabalho educativo com a música na educação infantil requer do professor consciência e conhecimento teórico, para que cumpra sua função de instrumento cultural que desenvolve o psiquismo humano. Desta forma, essas práticas pedagógicas explorando o universo musical, é uma possibilidade de mobilização da humanização, que pode alcançar crianças que, diversos fatores não são afetas pelas práticas pedagógicas hegemônicas na atualidade.

\section{Considerações finais}

O universo musical é extenso e amplo, pensar em atividades que permitam o trabalho com a música enquanto linguagem e como ferramenta para a humanização das gerações mais novas são práticas pedagógicas diferentes e ousadas. $\mathrm{O}$ trabalho com a música na educação infantil, não tem o objetivo de desenvolver um musicista, no qual a criança aprenda as 
DOI 10.33872/revcontrad.vlnl.e003 | v. 1, n. 1 | Jan./Jun. 2020

técnicas músicas e outras especificidades. Nessa etapa o docente deve pensar no desenvolvimento das especificidades humana, tais como coordenação motora, funções psicológicas superiores, desenvolvimento da linguagem, estimulação dos sentidos, etc. utilizando a música como ferramenta cultural que promove desenvolvimento humano.

Nesse sentido, não estamos falando de usar a música como "muleta" para trabalhar outros conteúdos de outras disciplinas, ou apenas para desenvolver aptidões humanas. Da mesma forma, insistimos que ela não deve somente ser abordar na abordagem da linguagem musical, com suas características especificas, de timbre, ritmo, intensidade, de aprender tocar ou cantar. Então, propomos uma superação dessa dicotomia, a fim de valorizar mais essa criação do ser humano, que se transformou junto com seu criador e pode transformar a vida de muitas pessoas, sejam bebês, sendo utilizada como ferramenta cultural que promove desenvolvimento humano, ou enquanto expressão cultural que sensibiliza e mobiliza emoções, sentimentos, pensamentos, em prol das necessidades humanas.

Pensando nisso, o nosso anseio é que o trabalho com a música seja intensificado na educação infantil. Dessa forma, será possível encaminhamentos metodológicos diferentes e inovadores, os quais podem dar oportunidades diferentes de aprendizados para os alunos. As práticas pedagógicas que exploram o universo musical têm a capacidade de estimular de formas diferentes o interesse, a motivação e a concentração da criança na atividade que está sendo realizada. Na educação infantil, isso é visto como um ganho para o desenvolvimento do psiquismo e de todas as aptidões humanas. Em outras etapas da educação básica, tais práticas podem dinamizar as aulas, possibilitando aulas mais divertidas e agradáveis, porém que não percam seu cunho cientifico de produção de conhecimento.

O contexto educacional, relacionado com o contexto sócio, político e econômico em que vivemos não contribui para práticas educacionais inovadoras. A pressão do mercado de trabalho, a "crise de identidade" de muitos docentes, que não sabem qual a sua função dentro da sala de aula, o que contribui para uma reprodução de metodologias, muitas vezes ultrapassadas, que estão fracassando dentro das classes e influenciando na eficiência da educação brasileira.

Assim, tais práticas, utilizando a música como linguagem e como ferramenta cultural para o desenvolvimento humano de modo integral, bem como outros encaminhamentos que saem do "padrão" hegemônico, podem ser uma alternativa para que a educação possa ter mais qualidade e cada vez mais caminhar para a real necessidades das crianças. Bem como, são também excelentes ferramentas mobilizadoras de desenvolvimento psíquico, as quais, contribuem para a humanização das novas gerações, com o objetivo de possibilitar para as 
DOI 10.33872/revcontrad.vlnl.e003 | v. 1, n. 1| Jan./Jun. 2020

crianças, um suporte adequado durante o seu desenvolvimento infantil, e que este seja ofertado integralmente. Consideramos que esse trabalho não esgota a temática abordada e abre caminho para nossas pesquisas e investigações sobre práticas pedagógicas com música.

\section{REFERÊNCIAS:}

ABRAMOVAY, M., KRAMER, S. O rei está nu: um debate sobre as funções da pré-escola. Cadernos CEDES, nº 9. São Paulo. 1986.

BARROS, G. de A. Vigotski e a arte na escola: um potencial educativo. In: GASPARIM, J. L.; MASHIBA, G. C. X. (Org.). Os clássicos e a educação: um retorno necessário em tempos de crise. Curitiba: CRV, 2019.

BENNETT, R. Uma breve história da música. Roy Bennett; tradução, Maria Tereza Resende Costa. Rio de Janeiro: Jorge Zahar, 1986.

BRASIL. Constituição da República Federativa do Brasil. Presidência da República. Brasília - DF, 5 de outubro de 1988.

BRASIL. Estatuto da Criança e do Adolescente. Câmera dos Deputados, Lei no 8.069, de 13 de julho de 1990. DOU de 16/07/1990 - ECA. Brasília, DF.

BRASIL. Lei de Diretrizes e Bases da Educação Nacional. Lei número 9394, 20 de dezembro de 1996.

BRASIL. Ministério da Educação. Secretaria de Educação Básica. Diretrizes Curriculares Nacionais para a Educação Infantil. Brasília: MEC/SEB, 2010.

ELMERICH, L. História da música. São Paulo: Fermata do Brasil, 1973.

FREIRE. V. L. B. A História da Música em Questão: Uma Reflexão Metodológica. Revista Música. São Paulo, 1994.

JEANDOT, N. Explorando o universo da música. São Paulo: Scipione, 1997.

LEONTIEV, A. O Homem e a Cultura. In: O desenvolvimento do psiquismo. 2. Edição. São Paulo: Centauro, 2004.

LEONTIEV, A. N. O Desenvolvimento do Psiquismo. Lisboa: Livros Horizontes, 1978.

MARTINS, L. M. O ensino e o desenvolvimento da criança de zero a três anos. Campinas - SP: Alínea, 2009.

LURIA, A. R. Pensamento e Linguagem: as últimas conferencias de A. R. Luria. Artes Medicas, Porto Alegre, 1987.

MENDONÇA, F. W. A organização da atividade de ensino como processo formativo do professor alfabetizador: contribuições da Teoria Histórico Cultural. Maringá, 2017.

PAUlA, E. M. A. T.; MENDONÇA, F. W. Psicologia do Desenvolvimento. Curitiba: IESDE Brasil S.A., 2009.

ROCHA, V. C.; BOGGIO, P. S. A música por uma óptica neurocientífica. Per music [online]. 2013, n.27, pp. 132-140. http://dx.doi.org/10.1590/S151775992013000100012. Acesso em: 29 de maio de 2018.

SCHERER, C. A. A contribuição da música folclórica no desenvolvimento da criança. Goiânia, 2010. 
TOMASELLO, M. Origens culturais da aquisição do conhecimento humano. Tradução: Claudia Berliner. São Paulo: Martins Fontes, 2003.

VIGOTSKI, L. S. A formação social da mente. São Paulo: Martins Fontes, 1998.

VIGOTSKI, L. S. A construção do pensamento e da linguagem. São Paulo: Martins Fontes, 2001.

${ }^{i}$ Doutor em Educação (UEM). Professor adjunto PPG/Psicologia/UEM. Email: fwmendonca@uem.br

ii Acadêmico do curso de graduação em Pedagogia (CRC-UEM). Email: ferwmen@ hotmail.com 